framum

Sociológico

\section{Forum Sociológico}

Série II

$34 \mid 2019$

Habitação nas áreas urbanas de Lisboa e Porto: Da comunidade aos decisores políticos

\title{
O papel do crowdfunding na dinamização do setor imobiliário
}

The role of crowdfunding in promoting real estate industry

\section{Miguel Neves Matias}

\section{(2) OpenEdition \\ Journals}

Edição electrónica

URL: https://journals.openedition.org/sociologico/4778

DOI: $10.4000 /$ sociologico.4778

ISSN: 2182-7427

Editora

CICS.NOVA - Centro Interdisciplinar de Ciências Sociais da Universidade Nova de Lisboa

Edição impressa

Paginação: 51-60

ISSN: 0872-8380

Refêrencia eletrónica

Miguel Neves Matias, «O papel do crowdfunding na dinamização do setor imobiliário», Forum

Sociológico [Online], 34 | 2019, posto online no dia 19 agosto 2019, consultado o 29 março 2022. URL: http://journals.openedition.org/sociologico/4778 ; DOI: https://doi.org/10.4000/sociologico.4778 


\title{
O PAPEL DO CROWDFUNDING NA DINAMIZAÇÃO DO SETOR IMOBILIÁRIO THE ROLE OF CROWDFUNDING IN PROMOTING REAL ESTATE INDUSTRY
}

\author{
Miguel Neves Matias \\ Instituto Politécnico de Leiria
}

\begin{abstract}
Resumo
A regulamentação recente do crowdfunding em Portugal vem chamar a atenção para o contributo efetivo que este instrumento pode representar para o desenvolvimento e sustentabilidade do setor imobiliário. O presente artigo tem como objetivo discutir as virtualidades do crowdfunding no financiamento de projetos imobiliários, num contexto em que o setor imobiliário perdeu dimensão nos últimos anos, com todas as externalidades negativas que daí advieram, a par com um sistema bancário que tem vindo a reduzir a sua exposição a este setor.

São analisadas as várias fontes de financiamento do setor imobiliário, alternativas ao crédito bancário tradicional, sendo focada a atenção no crowdfunding. Partindo da análise apresentada, são apresentadas, em detalhe, as várias modalidades de crowdfunding existentes, o seu modo de funcionamento e as implicações práticas para a industria imobiliária, evidenciando os seus pontos fortes e as suas debilidades.

Conclui-se que o crowdfunding proporciona investimentos mais transparentes, acessíveis, éticos, inclusivos e menos especulativos, mas, dado o seu histórico ainda reduzido, levantam-se várias interrogações acerca do que poderá vir a ser o seu verdadeiro posicionamento e relevância no financiamento imobiliário.
\end{abstract}

Palavras-chave: crowdfunding imobiliário, investimento imobiliário, financiamento pela internet, plataformas de investimento

\begin{abstract}
The recent regulation of crowdfunding in Portugal draws attention to the effective contribution that this instrument can have to the development and sustainability of the real estate business. The purpose of this article is to discuss the potential of crowdfunding in the financing of real estate projects, in a context in which the real estate sector has lost dimension in recent years, with all the negative externalities that have arisen, along with a banking system that has been reducing credit exposure to this sector.

We analyze the various sources of real estate financing that are alternative to traditional bank credit, focusing on crowdfunding. Based on this analysis, we present in detail the various categories of crowdfunding, their mode of operation and the practical implications for the real estate industry, highlighting their strengths and weaknesses.

We conclude that crowdfunding enables investments that are more transparent, accessible, ethical, inclusive and less speculative. But given its small track record, issues arise about what could be the position and relevance of crowdfunding in the real estate financing market.
\end{abstract}

Keywords: real estate crowdfunding, real estate, internet based finance, investing platforms

\section{Introdução}

A crise financeira global de 2008 obrigou à reanálise, elaboração e implementação de um conjunto de medidas de caráter regulatório que passaram a restringir significativamente a exposição creditícia dos bancos ao setor imobiliário. A partir daí assistiu-se no sistema bancário a uma muito maior diferenciação em termos de requisitos regulatórios de capital, entre crédito de bom e mau risco, desencadeando pela generalidade dos operadores no mercado uma análise de risco mais conservadora e um foco comercial muito direcionado para as melhores empresas e com algum histórico 
no mercado, colocando muitas empresas e projetos empresariais, em particular os direcionados para o setor imobiliário, arredados do canal de crédito bancário.

Com efeito, constatou-se que não só o balanço dos bancos foi significativamente afetado por imóveis que foram perdendo valor ao longo do tempo, como se verificou que grande parte do incumprimento estava concentrado em promotores e investidores imobiliários. A crise ensinou de uma forma dura, mas convincente, que investimentos imobiliários devem ter fontes de financiamento mais diversificadas e menos assentes em dívida.

Tradicionalmente, o financiamento para grandes projetos imobiliários advinha de um conjunto reduzido de bancos com vocação imobiliária. Essas grandes entidades tinham habitualmente limites avultados de capital, disponíveis para empréstimos ou investimentos nesse setor. No entanto, uma forte mudança nas políticas de crédito dos bancos no pós-crise mudou o mindset de todo o mercado de capitais. Esta mudança causou uma lacuna de financiamento para imóveis e empreendimentos urbanos. Os bancos que financiavam grandes projetos pré-crise registaram inclusivamente grandes dificuldades no financiamento de outros setores no pós-crise (Agarwal et al., 2010), reforçando o efeito de contágio, e até sistémico, que o incumprimento verificado no crédito imobiliário provocou.

Face às crescentes exigências de Basileia, os bancos tentam aumentar a sua solvabilidade, limitando os financiamentos aos setores de atividade que consomem mais capital, ou seja, aos mais arriscados, donde se inclui o setor imobiliário.

O desenvolvimento de novos projetos imobiliários é por isso altamente pressionado pelo contexto financeiro da indústria. Os bancos cobram prémios mais elevados, condicionam o montante a financiar o LTV (loan-to-value ratio: rácio entre o valor a financiar e o valor do imóvel afeto como colateral) mais baixos e impõem covenants cada vez mais exigentes, como sejam a contratualização de vendas com prazo definido e arrendamentos antecipados rigorosos (Marchand, 2016). Como resultado, a obtenção de crédito está sujeita a maiores custos de financiamento (pressionando o valor de venda do imóvel) e exigências adicionais. Cada vez menos bancos estão disponíveis para financiar os grandes projetos imobiliários (i. e., a assumir uma concentração de crédito em projetos de grande dimensão), o que obriga investidores e promotores a adiar investimentos e a repensar e diversificar as suas estratégias de financiamento.

Este contexto ilustra a situação difícil dos mercados imobiliários que, perante a inexistência de alternativas, se reflete em propriedades subvalorizadas, na falência de promotores imobiliários, e conduz à emergência de novos instrumentos alternativos de financiamento que forneçam soluções de financiamento exequíveis para empreendimentos imobiliários.

No caso português, analisando especificamente as empresas do CAE 41 (promoção imobiliária e construção de edifícios) ${ }^{1}$, constata-se que o volume de negócios anual agregado nesta atividade, que atingiu um valor de 17,162 mil milhões de euros em 2008 distribuído por 32648 empresas, reduziu-se para cerca de metade em 2017 (8,826 mil milhões de euros) distribuído por 26299 empresas. Em 10 anos o saldo líquido negativo na quantidade de empresas a operar no setor foi de 6349 empresas. O Ativo $^{2}$ agregado do setor seguiu a mesma trajetória (tendo passado de 51 mil milhões de euros em 2008 para 28 mil milhões de euros em 2017).

De igual forma, o financiamento bancário afeto a este setor, que representava em média $50 \%$ do ativo das empresas até 2008 , sofreu também uma redução gradual no período, tendo diminuído para $41 \%$ em 2018. Consequentemente, a autonomia financeira (Capital Próprio/Ativo) destas empresas aumentou de $20 \%$ para $26 \%$ nesse período. O setor imobiliário perdeu dimensão, com todas as externalidades negativas que daí advieram, mas ganhou solidez financeira e uma nova forma de encarar e estruturar o investimento e consequente financiamento de novos projetos: menos dependente de dívida e com maior abertura a fontes alternativas de financiamento.

O presente artigo tem como objetivo discutir as virtualidades do crowdfunding no financiamento de projetos imobiliários, num contexto de emagrecimento do setor imobiliário e em que o sistema bancário, como principal e tradicional financiador, tem vindo a reduzir a sua exposição a este setor.

\section{Alternativas ao financiamento bancário}

Para lá do financiamento bancário, podemos identificar 5 fontes de financiamento de projetos imobiliários em crescente dinamismo (Baldwin, 2017):

\section{Forward funding}

De acordo com Wilkinson e Reed (2008), esta modalidade de financiamento envolve um investidor que concede um financiamento para o desenvolvimento a curto prazo de um projeto imobiliário, tendo em vista a sua aquisição futura.

Um investidor estará disponível a assumir o risco do desenvolvimento inicial de um projeto, se perspetivar um potencial de valorização que o acomode. $\mathrm{Na}$ ausência de um contrato de pré-arrendamento significativo, o financiamento a prazo pode reduzir a exposição do financiador ao risco de locação (entre outras formas de risco) associado ao potencial de valorização do arrendamento num mercado em alta. Embora o financiamento a prazo possa reduzir algumas componentes do risco do promotor, a sua 
antecipação pode permitir ao investidor beneficiar de alguma proteção do ativo, por via, por exemplo, de benefícios fiscais, em comparação com o financiamento numa fase mais avançada do ciclo de desenvolvimento do projeto.

Além disso, os investidores que pretendem tornar-se proprietários-ocupantes podem-se envolver no processo de desenvolvimento por meio do modelo "build to suit", no qual o promotor constrói as especificações pretendidas pelo futuro ocupante. Os proprietários industriais são habitualmente os clientes deste tipo de financiamento, além de alguns proprietários de nicho, como sejam os data centers e o setor da assistência médica (onde é menos provável que os requisitos de construção exigidos por estes proprietários sejam fornecidos por promotores [especuladores] num mercado aberto).

\section{Rendas de superfície}

Trata-se dos pagamentos periódicos do arrendatário ou utilizador de uma parcela de terreno ao seu proprietário, no âmbito de um contrato de longo prazo. Apesar de o arrendamento de superfície não ser um tema recente, nos últimos anos, o tratamento dado pelos investidores aos investimentos de renda fixa tornou-se cada vez mais inovador (Flood, 2013). Porque os investimentos imobiliários são vistos por muitos investidores como um investimento relativamente seguro, nos últimos anos vários fundos de investimento mais inovadores têm-se tornado mais ativos neste setor, adquirindo carteiras significativas (muitas vezes diretamente ao promotor, durante os estágios iniciais de um investimento) e impulsionando os retornos, através da sua alavancagem.

\section{Securitização}

A securitização é uma prática financeira que consiste no agrupamento e classificação de vários tipos de ativos financeiros em função do seu risco e valor económico (nomeadamente, títulos de crédito, tais como faturas emitidas e ainda não pagas [v. g., recebíveis], dívidas referentes a empréstimos, leasings, entre outros), convertendo-os em títulos padronizados negociáveis no mercado de capitais. A dívida é transferida para uma sociedade instrumental (special purpose vehicle - SPV) e vendida, na forma de títulos, a vários investidores. A securitização de ativos imobiliários tem assistido a vários desenvolvimentos nos últimos anos, incluindo fundos de propriedade única, empresas de propriedade de ativos únicos e fundos de investimento imobiliário.

Wilkinson e Reed (2008) observam a crescente atividade em técnicas de financiamento de capital nos últimos anos nos mercados financeiros, na tentativa de reduzir muitos dos problemas inerentes ao modelo de financiamento imobiliário, como sejam a falta de liquidez, falta de comparabilidade com outras classes de ativos, falta de um mercado único, falta de transparência e o grande volume de capital exigido por muitos empreendimentos imobiliários. A proliferação deste instrumento pode aumentar a oferta de capital disponível para o promotor durante o processo de desenvolvimento.

\section{Mercado secundário}

De acordo com Baldwin (2017), com o eclodir da crise financeira global de 2008, nos EUA, a percentagem dos empréstimos imobiliários com incumprimento nos bancos aumentou cerca de $94 \%$ entre o quarto trimestre de 2005 e o segundo trimestre de 2010, caindo drasticamente a partir daí. Uma das consequências foi o aumento significativo do mercado secundário de empréstimos imobiliários, à medida que os bancos tentavam transferir a sua dívida subvalorizada para novos investidores. Os investidores conseguiram assim adquirir carteiras de empréstimos com incumprimento junto dos credores, com o objetivo de, entre outras estratégias de valorização, reestruturar os financiamentos associados aos investimentos imobiliários, assumir o controlo do(s) ativo(s) e/ou continuar o processo de desenvolvimento dos projetos ${ }^{3}$.

É provável que este mercado secundário mantenha algum dinamismo a médio prazo, de acordo com Baldwin (2017), particularmente no sul da Europa, uma vez que vários bancos europeus, passada a crise financeira, mantêm ainda um volume crescente de empréstimos em incumprimento nos seus balanços. Da mesma forma, o mercado secundário de participação privada acionista em projetos imobiliários (conhecido como "real estate private placement market") tornou-se também mais frequente nos últimos anos, em que fundos especializados têm vindo a adquirir participações em investimentos imobiliários ainda em desenvolvimento, diretamente a investidores que participaram na fase inicial e pretendem realizar capital antes da conclusão do projeto imobiliário.

\section{Crowdfunding}

O crowdfunding democratiza e avança um passo no processo de securitização (Baldwin, 2017), através de um processo que tem sido descrito como "um esforço coletivo de consumidores que fazem o networking e juntam dinheiro, geralmente pela internet, para investir e apoiar os esforços iniciados por outras pessoas ou organizações" (Ordanini, Miceli, Pizzeti \& Parasuraman, 2011, p. 443). Através de uma plataforma que intermedeia o processo de captação de capital, um empreendedor obtém capital externo junto da "multidão" (ou seja, o público em geral), em alternativa à captação de capital junto de um único investidor institucional ou de um pequeno 
sindicato de investidores (Belleflamme, Lambert \& Schwienbacher, 2014).

O crowdfunding começou inicialmente por ganhar popularidade e importância no financiamento de projetos sociais, startups e todo o tipo de negócios inovadores (Howe, 2006), cujo acesso às fontes tradicionais de financiamento se afigurava difícil ou mesmo impossível (Jenik, Lyman \& Nava, 2017), dada a ausência de histórico e/ou colaterais e dificuldades diversas em assegurar um cash-flow considerado aceitável para esses financiadores tradicionais (Schwienbacher \& Larralde, 2010).

Em Portugal, o crowdfunding deu os seus primeiros passos em 2011 através do surgimento de duas plataformas vocacionadas para a angariação de financiamento para projetos sociais ou pequenos projetos pessoais de cariz empresarial: a ppl. pt e a massivemov.pt. O seu enquadramento legal despertou as primeiras atenções em 2013, através da criação do Projeto de Lei n.o 419/XII, do Partido Socialista. Em agosto de 2015 foi aprovada a Lei n. ${ }^{\circ}$ 102/2015, que veio regular a atividade de "financiamento de entidades, ou das suas atividades e projetos, através do seu registo em plataformas eletrónicas acessíveis através da internet, a partir das quais procedem à angariação de parcelas de investimento provenientes de um ou vários investidores individuais" (art. 2.0 ${ }^{4}$

No que se refere ao investimento imobiliário, o crowdfunding está entre os mais recentes instrumentos de financiamento chegados ao mercado, tendo começado a mostrar os primeiros resultados, e consequentemente a despertar atenção, a partir de meados de 2014. Em julho desse ano foi concluída aquela que é considerada a primeira grande operação de crowdfunding imobiliário, quase sem publicidade, quando um grupo de 85 investidores particulares ficou com $15 \%$ da propriedade do Hotel Hard Rock de Palm Springs na Califórnia por 1,5 milhões de dólares 5 .

Contudo, a operação mais relevante, até à data, foi concretizada um ano depois. Wang Jianlin, um dos homens mais ricos do mundo, conseguiu angariar, através do seu conglomerado empresarial Dalian Wanda, em junho de 2015 e em apenas três dias, 5 mil milhões de yuans (805 milhões de dólares, aproximadamente), destinados à construção de um mega complexo imobiliário composto por cinco centros comerciais, através de crowdfunding, evitando as incómodas e morosas reuniões com investidores ${ }^{6}$. Nessa campanha de captação de fundos através da internet, era proposta aos investidores uma taxa de retorno anual de $12 \%$ (via rendas recebidas), mediante um investimento mínimo de 160 dólares e uma recuperação do investimento após 5 ou 6 anos, através da venda dos imóveis.

Desde então, e principalmente após a operação do grupo Wanda, o crowdfunding imobiliário, conhecido por real estate crowdfunding (doravante designado RE crowdfunding), parece evidenciar que pode ter um papel importante na dinamização do setor imobiliário, por via da maior capacidade de dispersar e diluir o risco do imobiliário por múltiplos investidores, na redução da volatilidade do seu preço e consequentemente na minimização de crises económicas sistémicas.

Em Portugal, o RE crowdfunding ainda está numa fase inicial, encontrando-se a funcionar a housers. com, uma plataforma de origem espanhola, constituída em 2016 (que entrou no mercado nacional em agosto de 2017) e as portuguesas portugalcrowd.pt e izilend.com.

\section{Modo de funcionamento do crowdfunding}

O financiamento colaborativo (ou crowdfunding) é (mais) um instrumento de captação de recursos que o poder da internet, no âmbito da economia da partilha, colocou ao serviço do empreendedor (Bailey \& Bakos, 1997), e que se materializa no facto de um conjunto de pessoas apoiar financeiramente e de forma direta um projeto, mediado por uma plataforma especializada, que se encarrega de o difundir e apresentar à comunidade, recolher desta o capital solicitado e entregá-lo ao empreendedor.

Podemos então identificar três figuras no crowdfunding: o beneficiário que desenvolve o projeto a ser financiado; a multiplicidade de investidores "anónimos" que financiam o projeto; e a plataforma de negociação que funciona como intermediário entre o beneficiário e os investidores. Uma particularidade importante nas operações de crowdfunding é a de que a operação só é considerada fechada (i. e., o montante angariado só será entregue ao beneficiário) se a totalidade do montante pretendido for angariado no prazo definido. Só nesse caso os investidores interessados no investimento são chamados a contribuir ou a colocar os montantes numa conta de depósito escrow?

Não se atingindo o valor global definido, estes não são chamados com as entradas (o sistema funciona sob uma espécie de procura prévia de intenções) ou, se tiver havido alguma contribuição, procede-se à sua restituição.

O crowdfunding pode assumir quatro modalidades: donation, reward, debt e equity, que apresentam diferentes formas de contribuição, retorno e motivações de investimento, conforme descrito no Quadro 1.

O RE crowdfunding assume as modalidades de debt crowdfunding ou equity crowdfunding, pois ora o investidor financia uma parte de um determinado projeto imobiliário, recebendo juros e o capital emprestado no final de um determinado período previamente acordado entre as partes, ora se torna dono de uma participação do projeto, recebendo 
Figura $1 \triangleright$ Modo de funcionamento de uma plataforma de crowdfunding

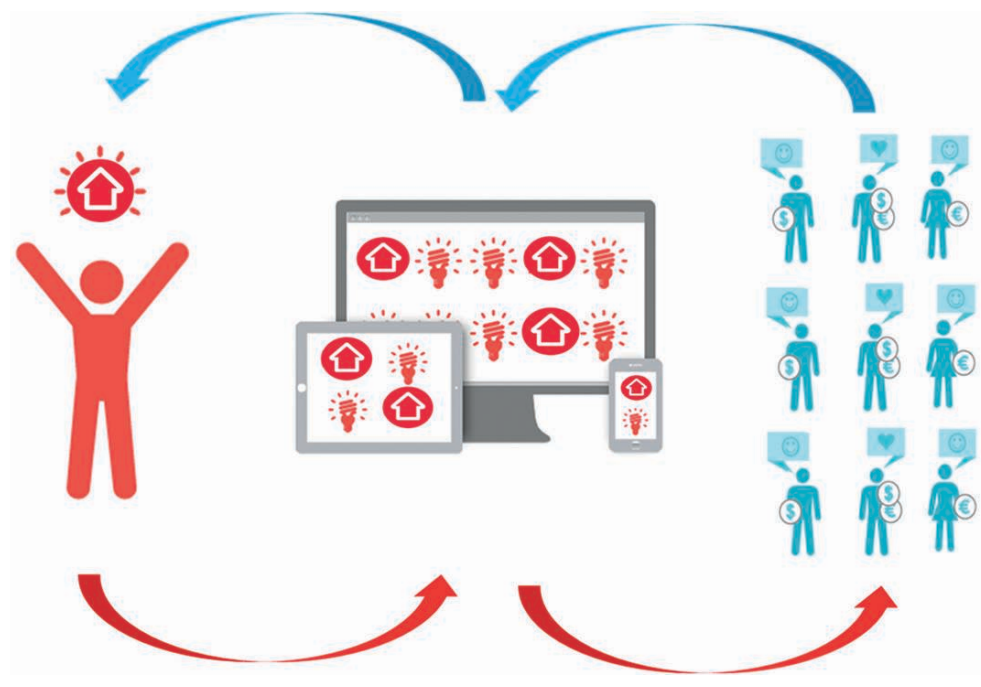

Fonte: Crowdfunding system in https://www.mipise.com (acedido em 19-10-2017) (adaptado) tal diretamente junto do grande público. Os investimentos podem compreender valores mobiliários da empresa promotora, não se referindo a nenhum projeto em particular, mas são mais comummente estruturados como títulos de um projeto imobiliário específico, através de uma sociedade instrumental criada para o efeito (SPV).

As plataformas lideradas por investidores captam o capital e realizam o trabalho de due diligence para avaliar a credibilidade e adequação dos promotores e dos projetos, antes de os listar nas plataformas e, uma vez aceites, fornecem aos potenciais investidores uma análise detalhada do projeto e do investimento, para suporte à tomada de decisão.

Quadro $1 \triangleright$ Modalidades de crowdfunding

\begin{tabular}{l|l|l|l}
\hline \multicolumn{1}{c|}{ Modalidades } & Contribuição & \multicolumn{1}{c}{ Retorno } & \multicolumn{1}{c}{ Motivações do investidor } \\
\hline $\begin{array}{l}\text { Donation } \\
\text { crowdfunding }\end{array}$ & Donativo & Benefícios intangíveis & Apoio de causas com as quais se identifica \\
\hline $\begin{array}{l}\text { Reward } \\
\text { crowdfunding }\end{array}$ & Donativo & $\begin{array}{l}\text { Recompensa não financeira: brinde } \\
\text { ou exemplar de produto ou serviço } \\
\text { apoiado }\end{array}$ & $\begin{array}{l}\text { Combinação da motivação intrínseca e so- } \\
\text { coma ótima forma de testar produtos no } \\
\text { umercado e avaliar o interesse do público na } \\
\text { mercaça }\end{array}$ \\
\hline $\begin{array}{l}\text { Debt } \\
\text { crowdfunding }{ }^{9}\end{array}$ & Empréstimo & $\begin{array}{l}\text { Reembolso futuro do empréstimo } \\
\text { com ou sem juros }\end{array}$ & $\begin{array}{l}\text { Obtenção de retornos superiores aos obti- } \\
\text { dos no mercado }\end{array}$ \\
\hline $\begin{array}{l}\text { Equity } \\
\text { crowdfunding }\end{array}$ & Investimento & $\begin{array}{l}\text { Participação societária e/ou o direi- } \\
\text { to de receber parte dos lucros }\end{array}$ & $\begin{array}{l}\text { Participação direta num projeto empresa- } \\
\text { rial, podendo ainda aliar à participação fi- } \\
\text { nanceira a intervenção na sua gestão }\end{array}$ \\
\hline
\end{tabular}

os rendimentos gerados, como sejam as rendas e outros rendimentos gerados pelo investimento, respetivamente.

A plataforma deve apresentar uma proposta de valor de forma estruturada que inclua a tipologia de investimento (hotel, retalho, multifamiliar), estrutura do investimento (capital [equity] ou dívida [debt]), proposta de investimento (valorização do investimento; taxa de juro); duração e estratégias de saída, entre outros detalhes.

Em termos do modelo de negócio de RE crowdfunding, as plataformas enquadram-se em plataformas de promotor e de investidores (O'Roarty, 2016).

Por plataformas do promotor entendam-se as plataformas lideradas e dinamizadas por instituições ou grandes empresas imobiliárias com uma marca reputada, capazes de, autonomamente, obter capi-
Os investimentos podem ser feitos direta ou indiretamente pela plataforma, sendo que considerações regulatórias poderão justificar a opção por determinado modelo de investimento, de acordo com O'Roarty (2016).

Nos modelos diretos, a plataforma atua como um mero intermediário financeiro ( $v$. g., corretor) e estabelece um relacionamento direto entre cada investidor individual e o promotor do projeto. Embora isso tenha vantagens para o promotor, ao estabelecer um relacionamento direto com um grupo de investidores que pode ser aproveitado para outros projetos, aumenta a complexidade da gestão do processo, pois o promotor deve reportar a cada investidor individualmente e garantir que os detalhes ou especificidades de cada contrato ou interação sejam satisfeitos. 
Para o investidor, tem a vantagem de reduzir os custos fixos no acesso ao investimento (poupa um prémio de intermediação). No entanto, atuar como um corretor tende a diminuir a responsabilidade da plataforma e, por sua vez, a profundidade da análise de due diligence requerida. O ónus recai sobre o investidor, que fica responsável por uma due diligence mais detalhada, enquanto a subsequente monitorização e gestão do investimento, para garantir que o promotor entrega o retorno acordado, é repassada para o investidor individual, que pode não ter o conjunto de competências necessárias para o fazer com a eficácia e eficiência desejáveis.

Esta abordagem é mais comum na China, onde as plataformas não podem controlar o dinheiro afeto pelos seus clientes, leia-se investidores, aos projetos, funcionando apenas como geradoras de leads. Noutros mercados, os promotores imobiliários podem usar plataformas de crowdfunding para mobilizar capital, com o investimento a ser transacionado através da plataforma, mas a ser gerido diretamente pelo promotor. Essa forma de investimento direto é um modelo comum para grandes plataformas lideradas por empresas de grande dimensão, bem capitalizadas e com uma marca reputada e experiência comprovada no mercado imobiliário. Em vez de criarem a sua própria plataforma de crowdfunding, preferem associar-se a uma plataforma de crowdfunding já existente, por forma a aproveitar as suas capacidades tecnológicas ${ }^{10}$, de acordo com Manaktala (2015).

Os modelos indiretos transferem a função de plataforma de crowdfunding do corretor para o gestor dos ativos. Os compromissos individuais do investidor são mantidos numa conta de garantia até que o valor global do capital requerido para o projeto seja atingido. Uma vez alcançado, os fundos podem ser investidos, indiretamente, através de uma SPV, no caso de investimento em capital, ou diretamente na empresa financiada, no caso de investimento em dívida.

\section{RE Equity crowdfunding}

A plataforma procura promotores e projetos imobiliários com necessidades de capital, que considera adequados para serem promovidos (due diligence) junto do público investidor, que pretende adquirir uma participação societária no projeto. Não é apenas o investidor individual que é convidado a tornar-se investidor, vários modelos alternativos permitem que pequenos investidores invistam conjuntamente com capitalistas de risco e business angels ${ }^{11}$.

Os investimentos em capital exigem, para efeitos de maior proteção dos investidores, a existência de uma empresa que fica responsável pela gestão do investimento imobiliário (nominee) ${ }^{12} \mathrm{e}$ que intermedeia a relação entre a plataforma de crowdfunding e uma terceira entidade: uma SPV, detentora do projeto imobiliário. A SPV é uma empresa instrumental, independente da empresa promotora, cujo primeiro membro do balanço inclui a participação societária no investimento imobiliário; e o segundo membro, a dispersão do capital necessário à sua concretização pelos investidores. Esta empresa, ao obrigar à separação jurídica (do risco de insolvência) do promotor (e também da plataforma), tem como objetivo, entre outros, isolar os cash-flows do investimento e sobretudo evitar que esses ativos, em caso de insolvência do promotor, integrem a sua massa falida.

Figura $2 \triangleright$ Estrutura básica das operações de RE Equity Crowdfunding

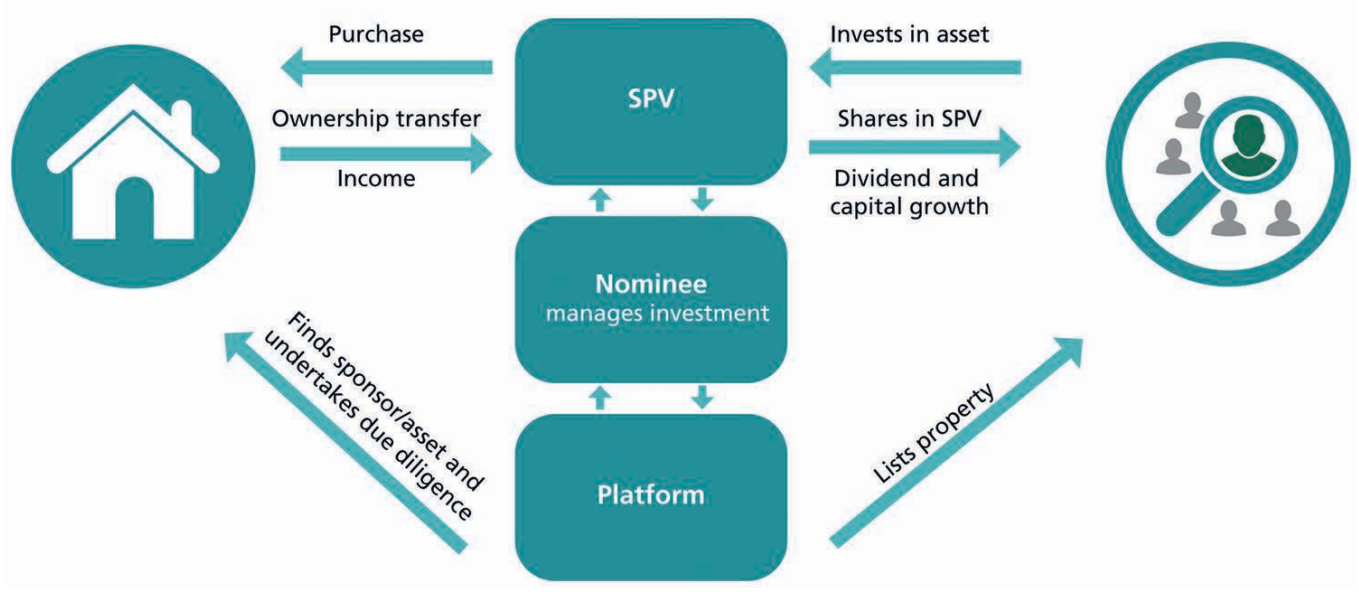

Fonte: O'Roarty (2016), p. 23 
A plataforma fica responsável pela monitorização do desempenho e do cumprimento dos requisitos legais envolvidos na montagem da operação de dispersão de capital e, após a venda do imóvel alvo de investimento, da regular liquidação da SPV.

Nesta modalidade, o investidor garante uma participação no capital da empresa que detém o imóvel e, como tal, o direito a auferir dividendos (por via das rendas imobiliárias) e outros potenciais ganhos de capital (mais-valias por via da venda do imóvel) ${ }^{13}$.

\section{RE Debt crowdfunding}

Na modalidade de debt crowdfunding, a plataforma, tal como no modelo anterior, analisa e seleciona os projetos imobiliários que necessitam de crédito, subscreve o montante necessário e promove a operação de financiamento junto do público, que pode ser colateralizada pelo imóvel alvo de financiamento ${ }^{14}$. Subcontrata também, à semelhança do que foi referido no RE Equity crowdfunding, uma empresa que fica responsável pela gestão do investimento (nominee), que, por sua vez, recorre a uma instituição financeira que irá gerir o empréstimo (criação da conta do investidor/financiador individual destinada a pagamentos e depósitos de valores - investor account) e que terá a vantagem de evitar dificuldades aos credores, perante a eventual insolvência da plataforma (Catarino, 2017).

O investidor seleciona os seus parâmetros preferenciais de risco, maturidade, entre outros, por exemplo, empréstimos de taxa fixa ou variável, e a plataforma autoaloca uma carteira diversificada de empréstimos ao investidor, alinhada com as suas preferências. O investidor atua como mutuante, pelo que a entidade financiada (mutuário) terá de pagar os juros e reembolsar o capital nas condições previstas contratualmente.

Um dos inconvenientes geralmente apontado ao RE Debt crowdfunding, segundo O'Roarty (2016), centra-se no intervalo de tempo que medeia entre a apresentação do projeto e a concretização do financiamento pretendido, o que reduz a capacidade da plataforma de captar e concretizar novos promotores e investimentos e, consequentemente, a sua viabilidade. Como resultado, muitas plataformas procuram pré-financiar os negócios e depois dispersar a operação de financiamento junto dos investidores, aumentando assim a sua atratividade. As principais plataformas consideram o pré-financiamento um componente essencial da sua sustentabilidade e do seu crescimento, em particular quando estão em causa investimentos de maior dimensão e qualidade. Além disso, a operacionalização do modelo de empréstimo acarreta alguns desafios jurídicos relacionados com a constituição e execução de garantias reais, quando estão em causa múltiplos investidores, por exemplo.

\section{Implicações do RE crowdfunding para o setor imobiliário}

O RE crowdfunding "democratiza" o acesso ao investimento imobiliário. Atrai pela oportunidade de investimento com pequenos montantes, pelo maior detalhe e transparência da informação relativa ao projeto, pelos custos de acesso mais baixos (desintermediação de consultores financeiros e outros prestadores de serviços da área imobiliária) e, claro, pelos retornos esperados mais atrativos.

A maior transparência (ou menor opacidade) destas operações é atrativa tanto para investidores como para promotores, em alternativa a outras

Figura $3 \triangleright$ Estrutura básica das operações de RE Debt Crowdfunding

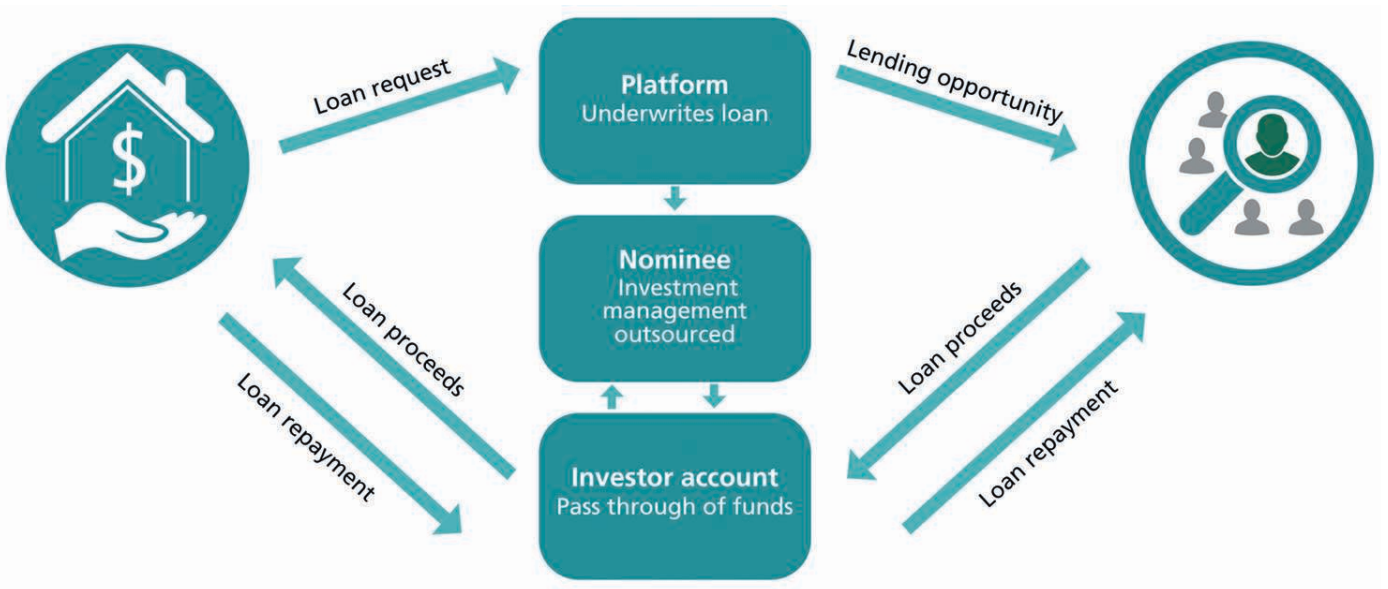

Fonte: O'Roarty (2016), p. 24 
fontes de financiamento. Os investidores recebem relatórios detalhados sobre o desempenho de cada investimento individual, enquanto os promotores beneficiam de um preço mais transparente na dívida que contraem ou no capital que angariam. Com efeito, a prazo, em função da relevância que estas plataformas possam vir a ter no mercado, é previsível que as fontes de financiamento tradicionais reajam e passem a disponibilizar soluções mais transparentes, com pricings e retornos mais comparáveis e/ /ou licitações mais competitivas.

No entanto, o mercado de RE crowdfunding também apresenta diversas deficiências. Desde logo, o fecho da transação só pode acontecer se a totalidade do capital solicitado for angariado, o que constitui um entrave para investidores e promotores com investimentos de maior dimensão.

Além disso, o mercado de RE crowdfunding não é ainda diretamente comparável com a indústria de CRE (comercial real estate), devido à sua dimensão reduzida e escopo consideravelmente mais estreito. De acordo com O'Roarty (2016), não é ainda possível comparar valores investidos via crowdfunding com os aplicados em fundos imobiliários, desde logo devido à discrepância dos montantes envolvidos e ao histórico dos diferentes instrumentos. Da mesma forma, os riscos e os retornos projetados, relativos a diferentes tipos de investimento em RE crowdfunding, diferem. Investimentos em dívida sénior, garantidos pela propriedade subjacente, apresentam um risco relativamente baixo para os investidores, uma vez que oferecem um alto grau de proteção de capital, em comparação com dívidas subordinadas e investimentos de capital, com menor proteção ao capital, mais risco, e por isso mais expostos à volatilidade dos preços ${ }^{15}$.

Para terminar, a fraca ou nula liquidez que estas aplicações financeiras apresentam, para o investidor que queira reaver o seu investimento fora das condições definidas ${ }^{16}$, constitui um outro entrave, que pode ser solucionado, em parte, com a criação de um amplo mercado secundário ${ }^{17}$. A possibilidade de posterior negociação dos valores mobiliários emitidos pelo beneficiário, através da criação e gestão de um mercado secundário organizado, permitirá que os investidores obtenham maior liquidez para o seu investimento, explorando mais rapidamente oportunidades de mais-valias e tornando também mais apelativas as ofertas, pela possibilidade de transação imediata, mitigando o seu risco.

\section{Conclusões}

O alcance da internet e a sofisticação tecnológica das plataformas existentes, a par com os baixos custos de transação, rapidamente vieram mostrar ao mundo que o crowdfunding não é mais uma moda passageira ou uma tendência dos novos tempos (onde imperam as redes sociais e as plataformas digitais), mas antes algo que veio para ficar ${ }^{18} \mathrm{e}$ que pode vir a tornar-se um concorrente sério dos instrumentos de financiamento tradicionais, caso os principais intermediários financeiros que os fornecem (onde se incluem os bancos e a indústria dos fundos de investimento e de capital de risco) não consigam incorporar no seu modelo de negócio a inovação e as virtualidades tecnológicas do financiamento participativo (Montgomery, Squires \& Syed, 2018).

As plataformas de RE crowdfunding despertaram a atenção do público investidor (ou aforrador) para os méritos do investimento imobiliário e dos promotores imobiliários, para a facilidade e transparência no acesso a capital.

Com efeito, perante a inexistência de opções de aplicação de capital interessantes junto dos canais tradicionais, estas plataformas aproveitaram o apetite de pequenos investidores não qualificados que procuram exposição à dívida e investimentos de capital no setor imobiliário e, consequentemente, proporcionaram também maior acesso a capital para promotores imobiliários que estavam arredados do canal de financiamento bancário ${ }^{19}$ (Kim \& Hann, 2018), sendo que a concretização sustentada e bem-sucedida destes ciclos de investimento, satisfazendo promotores e investidores, gerará um círculo virtuoso difícil de romper.

O RE crowdfunding está por isso a conseguir capitalizar novos investimentos imobiliários, em vez de os canibalizar. Ainda assim será importante perceber, em função do impacto do crowdfunding, a reação dos instrumentos tradicionais de financiamento imobiliário (onde se incluem bancos e fundos de investimento), perspetivando-se, a prazo, o surgimento de ofertas mais transparentes, acessíveis e flexíveis.

Do ponto de vista macroeconómico, pode igualmente contribuir para minimizar alguma especulação imobiliária (em particular em mercados onde a oferta imobiliária seja escassa devido à falta de financiamento para desenvolver novos projetos) e o aparecimento de crises bancárias sistémicas (Montgomery, Squires \& Syed, 2018), por via da menor participação e exposição dos bancos a projetos imobiliários de grande dimensão (a par com maiores mitigadores de riscos) e partindo do pressuposto de que os capitais aplicados via crowdfunding são capitais próprios dos seus investidores, não sendo propriamente consequência de contração de dívida, contribuindo também dessa forma para um sistema financeiro com menores riscos de contágio e por isso menos instável. 


\section{Notas}

1 Por consulta aos quadros de setor, disponibilizados na Central de Balanços do Banco de Portugal em https:// www.bportugal.pt/QS/qsweb/Dashboards (acedido em 27nov18).

2 Somatório de todos os recursos controlados por uma entidade sob a forma de bens e direitos, a partir dos quais se esperam influxos de caixa no futuro. Compreendem ativos correntes e não correntes.

3 Os investidores de capital de risco ( $v$. g., private equity) e de fundos altamente especulativos ( $v . g .$, hedge funds) tornaram-se particularmente ativos nesse mercado nesse período.

4 As modalidades de crowdfunding debt e equity (ver detalhes das várias modalidades existentes no Quadro 1) são alvo de regulamentação adicional específica através do Regulamento CMVM n. ${ }^{0}$ 1/2016, de 5 de maio, tendo também ficado incumbida a CMVM da sua supervisão e sanção.

5 https://eu.usatoday.com/story/dispatches/2014/04/16/ hard-rock-hotel-palm-springs-crowd-funding/7789073/ (acedido em 24nov18).

6 https://www.wsj.com/articles/chinas-wanda-group-raises-805-million-in-crowdfunding-push-1434687631 (acedido em 24nov18).

7 Estes contratos de depósito caraterizam-se por ter como base um acordo entre duas ou mais partes em que se confia a uma (geralmente um banco, mas pode ser um terceiro) a guarda e posterior restituição de bens móveis (valores mobiliários, numerário, títulos de crédito), consignados a um fim específico. No final do prazo (ou em face de um evento previamente acordado) procede-se à sua entrega a um terceiro ou à restituição ao depositante.

8 O crowdfunding funciona neste caso também como instrumento de marketing e screening de mercado, auxiliando os empresários a testar a popularidade do seu produto/serviço, ao mesmo tempo que asseguram financiamento para a empresa.

9 A par com o debt (ou lending) crowdfunding existe ainda o peer-to-peer $(P 2 P)$ lending. Enquanto no debt crowdfunding o objetivo é atingir um montante para financiar determinado projeto angariado junto de múltiplos investidores, no $P 2 P$ lending o objetivo passa por recorrer a uma plataforma online que se encarrega de reunir financiadores e tomadores de crédito que queiram realizar empréstimos diretamente entre si.

10 As plataformas de crowdfunding tentam rentabilizar o seu know-how tecnológico através do fornecimento de soluções de software como serviço. Por exemplo, as plataformas CrowdStreet.com, CrowdEngine.com e Katipult. com consentem que os promotores imobiliários instalem os seus próprios portais de marca, nestas plataformas, permitindo que alavanquem a sua própria base de investidores e exerçam controlo sobre a sua recetividade ao investimento, abrindo-se a um mercado mais amplo.

11 Plataformas como thesyndicate.vc e angelsden.com listam oportunidades de investimento nas quais investiram, por meio de redes online e offline. Os business angels fazem o pré-rastreio dos investimentos e realizam a sua due diligence de oportunidades e, em seguida, abrem o investimento nos mesmos termos ao grande público, através de um portal de crowdfunding.

12 Por exemplo, no Reino Unido, o requisito regulatório para garantir que os investimentos não sejam contaminados pelo risco de insolvência da plataforma resulta geralmente na afetação da responsabilidade da gestão das participações a uma nominee, empresa legalmente independente da plataforma.

13 Modelo de negócio da plataforma housers.com, em que por detrás de cada compra de um imóvel há uma sociedade que é constituída, o que significa que o investimento num imóvel, listado na plataforma, por um qualquer investidor, se traduz na aquisição de uma participação societária da sociedade que o detém ou na concessão de um financiamento a essa sociedade.

14 É o caso das portuguesas izilend.com e portugalcrowd.pt. Como exemplo, na portugalcrowd, de acordo com informação recolhida na sua página institucional http:// portugalcrowd.pt/wportcrowd/url/page/como-funciona (acedida a 02jan19), cada investidor, através de um contrato de mútuo, empresta diretamente ao proprietário do imóvel. Há uma rentabilidade preestabelecida para cada oportunidade: a partir de $6 \%$ ao ano, rentabilidade que é paga todos os meses. Cada imóvel é dado como garantia para o cumprimento do empréstimo.

15 Enquanto estes últimos investimentos oferecem retornos mais elevados, tem havido alguma preocupação por parte dos reguladores sobre se os riscos são adequadamente explicados aos potenciais investidores e se a exposição ao risco é apropriada para os investidores de retalho.

16 Por exemplo, o reembolso será feito via alienação do imóvel no final de um dado prazo, definido previamente.

17 De acordo com Catarino (2017), um mercado secundário dificilmente terá, no atual enquadramento legislativo, cobertura legal na generalidade dos Estados da União Europeia, como Portugal, dada a reserva legal de constituição de mercados regulados para valores mobiliários.

18 Em 2013, o Banco Mundial, no seu relatório intitulado Crowdfunding's Potential for the Developing World, estimava que o mercado global de crowdfunding em 2025 poderá chegar próximo dos 100 mil milhões de dólares, o dobro da indústria de capital de risco à data.

19 Em particular, as PME que pretendem desenvolver projetos imobiliários, o investidor individual que pretende dedicar-se ao mercado de arrendamento ou mesmo os cidadãos que pretendem desenvolver um projeto imobiliário comunitário continuam a registar restrições no recurso a fontes tradicionais de financiamento (O'Roarty, 2016).

\section{Referências bibliográficas}

Agarwal, S., Genay, H., \& McMenamin, R. (2010). Why aren't banks lending more? The role of commercial real estate (Chicago Fed Letter, 281) Chicago: The Federal Reserve Bank.

Bailey, J. P., \& Bakos, Y. (1997). An Exploratory Study of the Emerging Role of Electronic Intermediaries. International Journal of Electronic Commerce, $1(3), 7-20$. 
Baldwin, A. (2017). New developments in real estate financing. Economic Affairs, 37(1), 141-145.

Banco Mundial (2013). Crowdfunding's Potential for the Developing World. Washington, DC: Info Dev, Finance and Private Sector Development Department.

Belleflamme, P., Lambert, T., \& Schwienbacher, A. (2014). Crowdfunding: Tapping the Right Crowd, Journal of Business Venturing, 29(5), 585-609. doi: $10.1016 /$ j.jbusvent.2013.07.003

Catarino, L. (2017). Crowdfunding e crowdinvestment: o Regresso ao Futuro? Coimbra: Publicações CEDIPRE Online 32. Disponível em: http://www.cedipre.fd.uc.pt

Cole, M. (2015, junho 24). Could Asia's Richest Man Make REITs Obsolete? Forbes Asia. Disponível em: https://www.forbes.com/sites/michaelcole/2015/06/24/could-asias-richest-man-make-reits-obsolete/\#387319b13e93

Cowen, J. (2016). A study on the history and functionality of real estate crowdfunding. Joseph Wharton Scholars. University of Pennsylvania. Pennsylvania. Disponível em: https://repository.upenn.edu/joseph_wharton_scholars/19/ (acedido em 24mar18)

Flood, C. (2013, maio 19). Is ground rent investment built on solid foundations?. Financial Times. Disponível em: https://www.ft.com/content/affb1b8cbbe4-11e2-a4b4-00144feab7de

Howe, J. (2006, janeiro 6). The rise of crowdsourcing. Wired Magazine. Disponível em: https://www. wired.com/2006/06/crowds/
Jenik, I., Lyman, T., \& Nava, A. (2017). Crowdfunding and Financial Inclusion (CGAP Working Paper Março 2017). Washington, DC: CGAP.

Kim, K., \& Hann, I. (no prelo). Disillusion of the Democratization of Finance: Housing Prices, Collateral, and Online Crowdfunding. Information Systems Research, doi: 10.2139/ssrn.2334590

Manaktala, N. (2015). Democratising Finance: Digital Real Estate Investing Demystifed. Deal Index.

Marchand, F. (2016). Equity-based Crowdfunding Real Estate Markets, P2Report. Delft: Faculty of Architecture and the Built Environment, Delft University of Technology.

Montgomery, N., Squires, G., \& Syed, I. (2018). Disruptive potential of real estate crowdfunding in the real estate project finance industry: A literature review. Property Management, 36(5), 597-619.

O'Roarty, B. (2016). Real Estate Crowdfunding: Gimmick or Game Changer? Inglaterra: Investment Property Forum Research.

Ordanini, A., Miceli, L., Pizzeti, M., \& Parasuraman, A. (2011). Crowd-funding: Transforming Customers into Investors Through Innovative Service Platforms. Journal of Service Management, 22(4), 443-470.

Schwienbacher, A., \& Larralde, B. (2010). Crowdfunding of Small Entrepreneurial Ventures. In D. Cumming (Ed.), The Oxford Handbook of Entrepreneurial Finance. Oxford: Oxford University Press.

Wilkinson, S., \& Reed, R. (2008). Property Development. Oxford e Nova Iorque: Routledge.

Recebido a 31/10/2018. Aceite para publicação a 28/01/2019

Miguel Neves Matias (miguel.matias@ymail.com). Professor adjunto convidado. Escola Superior de Tecnologia e Gestão. Instituto Politécnico de Leiria. Morro do Lena, Alto do Vieiro, 2411-901 Leiria, Portugal. 